\title{
Humans, sharks, and the shared environment in the contemporary eco-doc
}

Helen Hughes

School of Arts, University of Surrey, Guildford, UK

Focussing on the film Sharkwater directed by Rob Stewart (2006) this article

discusses formal interpretive aspects of recent environmental documentaries which

are intended to raise awareness about environmental issues. It is argued that

contemporary environmental documentaries seek to persuade audiences to protect

the shared physical environment by increasing the amount of information and

imagery available to a shared cognitive environment. An integral part of this process

is the conscious awareness of attitudes towards information presented. In the case of

recent environmental films about threatened species it is argued that the inclusion of the human and the wild animal in the frame is a technique used to raise awareness of the complex questions concerning human attitudes towards other animals as well as towards other human beings. It is argued in particular that activist films are concerned to make visible the necessity for human cooperation in the protection of endangered species.

Environmental documentary, environmental awareness, wildlife conservation

\section{Introduction}

About three minutes into the opening credits of the environmental documentary film Sharkwater (2006), as part of a flowing sequence of images of swaying and swimming aquatic life, the director, Rob Stewart, is shown resting on one knee in clear water on the ocean floor, his arms around a shark. He appears to be holding the shark, which is not struggling, while he strokes its side. After about half a minute of footage the shark swims out of his grasp. In voiceover Stewart narrates his life story as a quest to overcome his fear and get to know the species which he has always admired for its beauty and great age: 'You're told your whole life, since you were a kid, "sharks are dangerous". You are warned about venturing too far into the ocean - but then finally you're under water, and you see the thing that you were taught your whole life to fear, and it's perfect, and it doesn't want to hurt you, and it's the most beautiful thing you've ever seen, and your whole world changes.' The sequence is striking. The water is deep blue, the shark classic in its sleek shape, the diver calm and skilled. Within the frame there is a utopian moment, a peaceful union of predators ancient and new. The human fear of the shark is visibly overcome and 
the diver, having conquered even his own heartbeat, discovers tranquillity, meaningfulness, togetherness.

Sharkwater is a film made independently over a number of years by an expert enthusiast who originally intended, as he states on one of the trailers to the film, to make a 'pretty picture' about his beloved sharks (Horizon Motion Pictures). The project turned into an environmental documentary as Stewart become aware of the economics of the shark fin industry that inhibited his own attempts to get closer to the sharks to film them and is in fact threatening the continued viability of the species. The independent nature of the film and the personal commitment of its director are characteristic for eco-docs of the first decade of the twentieth century that have increased in number and in quality as environmental issues have become more urgent and as activist filmmakers have developed ways and means of using film to represent issues in inclusive and compelling ways.

This sequence described above acts as an introduction to the issues discussed in this paper which is about the cinematic frame as a powerful device used by environmental documentary filmmakers to bring together objects in order to explore and communicate the effects of that conjunction. This potential in the medium has slowly emerged partly in response to institutional calls for the dissemination of environmental information initiated by the recommendations that followed the 1972 United Nations conference on the Human Environment (the Stockholm Conference) which set out a number of gargantuan tasks amongst which was the use of traditional and contemporary media to 'create the awareness which individuals should have of environmental issues'. (United Nations 1972) Wildlife and documentary film might be said to be naturally suited to the task of raising awareness about threatened species and environmental pollution, and yet, since 1972 it has become apparent that it is a struggle to find an effective way to create meaningful awareness across a broad spectrum of the population even in these media forms. Not only is there a potential ideological conflict for environmental campaigners between the values of the environmental community and the historical roles of film and television as public information vehicles, there has also been a reluctance on the part of wildlife film and television producers to acknowledge the issues and to compromise the popularity of their products through reference to the 
unpalatable realities of industrial impacts on wildlife and the natural environment (Blewitt 2010).

Nevertheless, in the first decade of the twentieth century three shifts have occurred to enable an increase in number of documentary films made about environmental issues. First has been the increased popularity of documentary film itself as a form. In the middle of the decade at the Grierson Awards in 2005 Nick Fraser, Storyville series editor at BBC Four, spoke about the extraordinary revival of documentary. In an interview on the series homepage online he puts this down to 'a reaction against the platitudes and stereotypes of television', 'the steadily lowering cost of equipment', and the fact that young people want to make and watch documentaries: 'It has become a very convenient form of self-expression and a contemporary cultural form' (BBC Storyville 2004). Second has been the development of a post ideological form of community activism, particularly in the United States, using the social networking potential of the internet to produce alliances between different interest groups to create critical mass (Christensen 2009; Lacleau and Mouffe 2001). Third has been the shift away from the focus on the preservation of wilderness and agricultural communities towards the argument that what is needed is a modernisation of both technology and environmental regulation to solve the environmental issues - including environmental justice issues - raised by the carbon economy.

The aim of this article, however, is not to discuss how the environmental documentary film, sometimes referred to as the 'eco-doc' in the popular press or included in ecological film in academic discourse, has emerged institutionally, but rather to consider and elucidate how visualisations of a shared physical environment in environmental documentary film seek to promote the popularity of activism, and environmental justice thus contributing towards the appropriate and adequate representation of environmental issues in the spirit of the Stockholm conference, and to propose that scenes such as the one described above represent a significant development in terms of its capacity to visualize the environment as a shared physical and imaginary space. Not only is the perspective in the frame expanded beyond the human to include that of the animal, the monologue accompanying the image strives to communicate the developmental specificity of the campaigner's history also. This move towards inclusive, personal, and exploratory approaches to 
environmental communication on film is typical of a current trend which I will characterize here as a move to visualize and hence realize the environmental community.

The focus in this article is thus on the analysis of film form as a vehicle for raising environmental awareness considering in particular choices about framing as critical in the composition of visual ideas which expand the cognitive environments of a community of viewers in ways which promote the possibilities for changes to social life which protect or even enhance the environment. This very broad characterisation of raising awareness is given narrower and more concrete definition by individual films which focus on particular causes such as the protection of wildlife, of small cetaceans, or, more specifically still, the protection of sharks and so on. By definition the focus in this research is on understanding the potential for the film frame to raise awareness rather than on testing audience's responses to specific films. The purpose is to look more closely at the significance of inclusion in the frame, taking the example of the inclusion of the shark and the human in the same shot, and discussing how such inclusion both creates and signifies shared physical and cognitive environments. Taking a step further, the signification of such shared environments is taken to be the source of the energy that drives the making of contemporary eco-docs seeking to embody their messages for global audiences.

This article will look at the film Sharkwater as an example of an eco-doc that attempts to raise awareness of environmental issues affecting a particular species of wildlife. Told from a first person perspective and clearly an attempt to reach a broad audience, the film negotiates a number of issues that have been raised by critics of wildlife representation in mainstream cinema. In his book Wildlife Film Derek Bousé (2004) has drawn attention to the ways in which popular films and programmes fail to represent the natural environment with any degree of realism, preferring instead to use dramatic structures and to anthropomorphise animals in order to maintain human interest. He also demonstrates the significant differences in attitudes towards the ethical treatment of humans and other species. Laura Marks (2002) has also criticized the values represented in mainstream wildlife documentary, pointing to the connections between the colonial occupation of territories and the protection of wildlife parks in contemporary postcolonial states. She argues that the wildlife populations in such parks are given a higher status than human populations. Bousé 
comes to the conclusion that wildlife film is not an appropriate form to educate the public about the natural world, although he does recognise a distinction between the environmental documentaries of filmmakers such as Jacques Cousteau and the wildlife film.

In addition to her postcolonial critique of mainstream films, contrasting such with a subgenre of experimental film that shows a variety of hunting relationships with animals typical of non-Western cultures, Marks is concerned with a tendency in Western countries labelled 'petishism'. This concern involves an inappropriate human identification with animals that comes out of the fear that we may be more like animals than we would like to admit. This results, she argues, in the sentimental representation of animals that projects human cognitive capacities onto them (2427). This critique is very important for films such as Sharkwater which seek to persuade audiences of the need for protective measures partly through asking them to think with less fear about the shark's point of view. The images of Stewart swimming with the shark are critical to its persuasive strategy.

Marks is also not the only critic to have argued for the representation of a more healthy distance between humans and animals in the media. In his chapter on David Attenborough's Blue Planet Sean Cubitt (2005) argues in favour of the presence of the apparatus of image making but the exclusion of the human being in the representation of the ecology of the oceans. Cubitt bases his arguments around the question of how nature is valued, making the decision about what to include in the frame a decision about how the objects in the frame are valued. Cubitt argues that Blue Planet, (Attenborough Originally transmitted 12.09.01-31.10.01) excludes the human from the frame in order to make 'the strongest ecological claim' about the value of nature which is 'for the intrinsic value of nature, a value not grounded in consciousness, as for example the way a plant values sunlight'. His argument in favour of the inclusion of the technology of image making seeks to put together knowledge and consciousness of nature that comes from the image with the awareness of the separation or alienation from nature that comes from the exclusion of the human from the world viewed. Out of this combination of knowledge and exclusion comes 'the ethical dialectic [...] between the unknown ecosystem which is a good in itself regardless of our knowledge, and knowledge which is also a good, regardless of its instrumental uses for human self-interest' (57). 
There are, then a wide variety of issues that arise out of the representation of wild animals and their relationship with human beings. What I propose to do here is to study the film in terms of the ways in which it raises awareness of the threat to sharks as a species by focusing explicitly on the current relationship between humans and sharks and asking audiences to evaluate this state of affairs. This strategy I will treat as an act of 'ostensive inferential communication' in the sense developed by Dan Sperber and Diedre Wilson in their book Relevance:

Communication and Cognition (1986/1995), a model which develops the idea of a shared cognitive environment as critical to communication. Sperber and Wilson's distinction between physical and cognitive environments will be used as a way to describe the use of a double frame in eco-documentary in which the environmental community is framed framing the environment. This approach, strongly reminiscent of cinéma vérité approaches to filming social life, includes the camera and crew in shots and encourages the idea of documentary filmmaking as a progressive experiment. At the same time, the passions of the filmmakers are expressed in the focus on wildlife, habitat, and on objects of environmental desire in the expression of a vision of a different relationship with the world. This double frame has interesting formal interpretive effects, in which the relationship between the inside and the outside of things is made manifest. In particular it acknowledges and allows for the ways in which individual spectators select and themselves frame the phenomena they perceive in the film representation. Sperber has described this complex human capacity for metarepresentation, arguing that 'The fact that humans are expert users of metarepresentations, is, I would argue, as important in understanding human behavior, as the fact that bats are expert users of echolocation is in understanding bat behavior' (Sperber: 2000). Environmental documentaries such as Sharkwater rely on the capacity for audiences to select and relate the information conveyed to their own understanding of the shared planet.

The discussion will introduce and elaborate the ideas with reference to the film, first introducing the idea of the shared cognitive environment, then discussing the visualization of shared physical environments, and shared cultural memory. The expansion of the shared cognitive environment as the purpose of the film will look at the revelatory frame in environmental documentary film, concluding with 
representations of shared concern for the physical environment as the generic ending of the eco-doc.

\section{Raising awareness, or sharing cognitive environments}

Dan Sperber and Dierdre Wilson's Relevance, Communication and Cognition is a theory formed as an attempt to create an explanatory model for how linguistic codes and contextual information interact in human interpersonal communication. Sperber and Wilson's theory of relevance was developed as an explanatory model to link the self-contained system of linguistic signs with contextual information in the momentto-moment process of interpersonal language use. As Torben Grodal argues in Embodied Visions (2009) this approach to linguistic pragmatics contrasts with the structuralist separation of systems and contents: 'Dan Sperber and Deidre Wilson (1986) argue that language cannot be explained in isolation from non-linguistic cognitive inference systems. The ability to draw inferences is based, for instance, on perception, so that the understanding of linguistic information bleeds into those general perceptual-cognitive-emotional-motor capacities that we use to understand the world' (14) Grodal does not elaborate on the complex issues involved in understanding the interactions or 'bleeding' between the linguistic code and inferential communication. Sperber and Wilson's work on this problem, however, can provide some insights into how the visual frame, interpreted as an ostensive act of communication, can start and direct the inferential process. As a starting point they grapple with the philosophical problem of mutual knowledge.

Raising awareness of social issues is understood here as the use of public media to increase the shared knowledge of a community about the broader context of specific issues. Anja Kollmuss and Julian Agyeman, in their survey of theoretical frameworks 'developed to explain the gap between the possession of environmental knowledge and environmental awareness, and displaying pro-environmental behavior' (3), also define environmental awareness as a matter of knowledge, of 'knowing of the impact of human behavior on the environment' (16), while defining knowledge as having 'both a cognitive, knowledge-based component and an affective, perception-based component' (16). Sperber and Wilson's questions 'What form of shared information is available to humans? How is shared information exploited in communication?' are 
also good starting points for understanding raising awareness. They begin their response to these questions with the statement: 'All humans live in the same physical world.' (38) This realist position connects with the structuralist position through the following fundamental assumptions about human beings which introduce the issues for human communication. 'We are all engaged in a lifetime's enterprise of deriving information from this common environment and constructing the best possible mental representation of it. We do not all construct the same representation, because of differences in our narrower physical environments on the one hand, and our cognitive abilities on the other.' (38) Sperber and Wilson elaborate on the problem of variation in individual mental representations of the physical world in the process building the concept of a 'mutual cognitive environment' (41) as a means to understand how individuals may communicate despite variations in language, memories and cultural experiences. Important to the concept of a mutual cognitive environment is their idea of manifestness, which is understood from a cognitive point of view as varying in degree. Sperber and Wilson explain, 'anything that can be seen at all is visible, but some things are much more visible than others.' (39) 'To the extent that two organisms have the same visual abilities and the same physical environment, the same phenomena are visible to them and they can be said to share a visual environment. Since visual abilities and physical environments are never exactly identical, organisms never share their total visual environments. Moreover, two organisms which share a visual environment need not actually see the same phenomena; they are merely capable of doing so.'(41) These definitions of manifestness do not in themselves create the possibility of a 'mutual cognitive environment' as it is possible for two organisms to pay attention to completely different aspects of the same physical world. The additional move required consists of a piece of information that comes out of the manifest environment itself. Using their two characters Peter and Mary, Sperber and Wilson explain: 'Peter and Mary are talking to each other in the same room: they share a cognitive environment which consists of all the facts made manifest to them by their presence in this room. One of these facts is the fact that they share this environment.' Sperber and Wilson point out that it is possible that the two characters may not make the assumption even though it is manifest to them, but once they do make it then a shared cognitive environment comes into existence. Critically, all inferential moves on the basis of that 
assumption, in other words the process of inferential communication itself, depend on the making of that first assumption about the shared environment.

A film frame clearly adds to the cognitive environment of the individuals watching it and through the delineation of space can be used to calibrate the relative manifestness of objects represented within the frame. Cognitive film theorists such as Edward Branigan (2006), Warren Buckland (2000), Joseph Anderson (1996) and Torben Grodal (2009), have sought to observe how the spectator processes the moving image as well as to discover underlying rules. Here it is worth stressing that even the film frame does not guarantee a shared visual - and further cognitive environment, to film viewers, but it creates the conditions for it, and, more significantly, it creates the conditions for a shared cognitive environment for film activists and their audiences. This cognitive environment includes not only the visual information, of course, but also the audible track and the manifest assumptions that follow.

Vivian Sobchack (1991) has carried out an analysis of film spectatorship from a phenomenological point of view, including the awareness of the apparatus of filmmaking and film viewing (the camera, the crew, the projector, the screen), and drawing attention in particular to the spectator's embodied physical responses to the film. Torben Grodal has produced a detailed model of cognition relating specifically to film which he has labelled the 'PECMA flow' in which perception and emotion precede cognition in a 'bottom-up' process which can be reversed by 'top-down aspects' such as prior learning. Both Sobchack and Grodal, like Sperber and Wilson, are at pains to point out the contingent and indeterminate nature of communicative processes. Sobchack's argument is to reassert the necessity and value of individual, subjective and embodied responses for the interpretation of films. Grodal is concerned to assert that 'cultural diversity and cultural development are compatible with the assumption of a biological human nature' (25). The use here of Sperber and Wilson's cognitive model of inferential communication is to bring in their concept of a mutual cognitive environment as a means to understand how environmental documentary, and activist film more generally, utilizes questions about shared cognitive environments in order to expand the debate about the shared physical environment. By altering the cognitive environment of audiences, environmental activist filmmakers seek to make more manifest issues which are less manifest or 
hidden in the day to day life of the community. Invisible underwater environments, for example, are made more manifest by environmental films. More than this, the films seek to make links between the day to day physical environments of spectators and the cognitive environments made manifest by their films so that the emotional impact of the film continues beyond the film experience itself.

\section{Visualizations of the shared physical environment}

In a documentary film such as Sharkwater, the footage discussed at the beginning of this article represents a recording of proximity in historical space, a moment of touching between a shark and a human being. We have more of an idea of what that moment meant to the human being as he is able to communicate its significance in words. The visual evidence, however, has an affective power which continues to reverberate through the image, embedded within the rhetorical structure of the film as a whole, allowing the viewer to identify with the shark as well as the person in the frame, provoking questions about the shark's perceptions and subjectivity, its sense of touch, hearing, of vision, of fear.

The image of the human and the shark touching one another in Sharkwater in a kind of embrace is presented in the film as a revelatory image that narrows the gap between humans and sharks in contemporary culture. In particular the film is at pains to point to the evidence that sharks are not aggressive towards humans and are, on the contrary, afraid of them. In encouraging empathy with the shark as well as the man, however, the problem of difference in the structure of experience arises, leading to the possibility of a false projection of feelings and perceptions onto the animal or a false transference of affections.

The film deals with these issues largely through a voiceover narrative that situates sharks as part of the evolution of life on earth, explaining their significant role in maintaining the balance of nature as the top predator in the oceans. In the process of explanation, facts about shark behaviour and perception are communicated, such as their poor sight, their enhanced sensitivity to sound and to the heartbeat of the human in particular, and their tendency to mistake human swimmers for injured seals - one of their natural prey. The work of the natural scientist in understanding the experience of the animal functions in the film not simply as pure knowledge but as 
part of an argument for reconciliation and the possibility of a shared space. Stewart suggests on one of the short films supplementing the DVD that the general public should be taught how to swim with sharks as they have learned to swim with dolphins, making the notion of shared space literal (Horizon Motion Pictures 2008a).

\section{Shared cultural memory}

At the same time as conveying this contemporary information on the shark species, the film seeks to explain and modify current public attitudes by including and discussing archive footage from a US Army film which offers advice on shark behaviour for soldiers who may find themselves in shark infested waters. At first it appears that this film is being used in a conventionally humorous way in order to debunk attitudes that have become dated. The anti-globalisation documentary The Corporation (Mark Achbar and Jennifer Abbot, 2003) does this to great effect with respect to business organisation, for example. However, the military information film is inserted into Sharkwater in its early scenes and, despite its opening line 'predator of the sea, terror of all men who enter the ocean, the very symbol of lurking danger, that is the shark!' it goes on to demonstrate an open and enquiring fascination and desire to know more: 'What is he really? We know little except the shark was here before the continents in their present shape were formed, before the dinosaur lived, and he is still here, essentially unchanged.' This film, then, which does offer some amusing scenes, in the way all instructional films do, of a soldier carrying out actions to deter sharks, represents a history of curious coexistence with the shark.

In contrast, representations of the shark in blockbuster films, particularly Spielberg's Jaws (1976) and the ensuing series, are discussed as having a significantly damaging and distorting effect on public perception, encouraging indiscriminate killing for sport and industry. While the instructional film contributes to the spectator's knowledge of the history of attitudes to the species, references to the blockbuster ask for consideration of attitudes, particularly for a reasoned approach to the suggestion that sharks should always inspire fear. Interviews with natural scientists, with fishing industry workers, and with the general public in the film reveal significant differences in knowledge of and attitudes to sharks.

The inclusion of Paul Watson in the film is a further controversial factor that for environmental activists draws attention to a longstanding battle over how to monitor 
and regulate activities on global waters. Paul Watson is introduced in the film as a role model for the director Rob Stewart, arguing that it is individuals who bring about change rather than political or academic institutions. The recent film Just Do It (Emily James, 2010) focuses on this idea in particular, offering a portrait of Watson as an example. The broader issues are about the borderline between using legal and illegal tactics in protecting species and habitats, although here in the film Sharkwater what is shown is not the general debate but an example of how Watson goes about attempting to stop illegal fishing, recounting the difficulties that ensue as an integral part of the story of how the film was made.

These reproductions of archival historical and contemporary moving image material relating to human/shark relationships and environmental activism put the images shot specifically for the film in high definition colour into a cultural historical context shifting the consideration of them into a meta-representational structure. Instead of thinking about the shark per se the spectator is to think about the representation of the shark in the material, and in the current film. Such mental representations might be 'This film from the 1960s shows me that it was then known that sharks are one of the oldest living things on earth.' 'Jaws is an exciting story but it misrepresents the shark as actively hostile to humans.' 'I can understand why Paul Watson uses the tactics he does.' 'The filmmakers want me to think about my attitude to sharks now, to see the contemporary images as beautiful, and to update my knowledge.' All this material explains and in some sense excuses the general public for the pervasive fear of the shark and acceptance of the need to kill them, preparing for the argument that the species is in need of special protective measures.

It is possible that as a spectator I may reject these arguments and reassert my belief in the hostility of sharks as rational and appropriately cautious. I may argue that I am not a tall, strong, trained diver able to regulate my heartbeat, for example. Nevertheless, the effect of the strategy, whatever my response, is to increase my awareness of the issues and of the current ideas. Disagreement does not negate the cognitive effect of the film or the possibility that the film can be used to generate a discussion after it has been shown.

\section{Expanding the shared cognitive environment}


The revelation of the shark as a non-hostile creature is the material that Stewart set out to convey in his original plan for his film. However, the process of making the film, and the discovery of illegal shark fishing and shark fin trading turns another set of images into a revelatory movement within the film. Images of the illegal and legal fishing of sharks, with industry workers cutting off their fins and throwing their dismembered bodies back into the water to save weight, provide a counterpoint to the utopian image of peaceful harmony between human and shark.

Towards the end of the film a legal fishing boat is shown on which an orange-clad worker is seen in slow motion laboriously dragging a small shark onto the deck. The formal structure of this shot differs from the opening shot in which Stewart embraces the shark. Here the point of view of the camera operator both above the water and below it is more noticeable. The action is captured from afar, the images are grainy and less well focused. The workers and the sharks are kept within the frame with difficulty, the workers have their backs to the camera and obscure the view to the sharks and to their own actions. The camera operator struggles to focus in on the body of the shark as the workers remove the fins with sharp knives. The formal structure of this shot thus differs from the opening shot in which Stewart embraces the shark. There the point of view of the camera operator is less noticeable, encouraging full enjoyment of the scene in front of the camera. In the filming of the shark-finning industry at work the positions are more complex and controversial. The film viewer might here take up the position of the camera operator who, imagined as an activist, is struggling to see what is happening and to gain the evidence needed for the film and for investigation, and who may be emotionally anguished at what is visible. This positioning of the spectator is encouraged by the first person story line which has demonstrated that the director has shot much of the footage shown. Edward Branigan (2006 36-39) discusses this as a tendency to personify or anthropomorphise the camera itself. Point of view is one of the most significant resources in film representations creating the opportunity for the spectator to believe in the possibility of imagining the world with a different mind and to test out such a position. Grodal discusses two models relating to the psychology of the perception of other people and their minds, theory of mind and simulation theory, and points to the ways in which the different models relate to point of view in narrative fictions. In stories using the first person perspective, simulation theory 
predicts a response 'in which emotions and action tendencies derived from the self, that is, first-person emotions, are activated.' (2009 188) For awareness raising, this possibility feeds into the idea that a film can dramatise for a viewer what it would be like to be an activist, to participate in activism. Thus the point of view of the camera operator as represented by the viewer may be difficult, mentally painful, but meaningful, and perhaps fulfilling.

The position of the worker is another possible perspective to take although the film at this point does not encourage simulation. As Grodal explains 'in descriptions of a conflict between self and other, as in the phrase "I hit him," the third person has become an object and as such ceases to activate first-person experiences of agency.' (188) Earlier in the film the protagonists communicate with some workers who are struggling to make a living out of what looks like a difficult and unpleasant job which also exposes them to the dangers of decompression through diving too deeply and surfacing too quickly. This is the point of view that Laura Marks might argue is that of the human 'other' in the film, valued less than the animal other, the shark. Viewers of the film, like some participants in the film, clearly do take the position of the workers, pointing to cultural difference as an argument against the need for species protection. They would appear to be constructing a more complex response to the film in which it is observed that the workers are pushed into a third person perspective by the strategies engaged by the filmmakers. As Grodal puts it 'fortunately, it seems that we possess the ability both to simulate and perform thirdperson TOM-based [Theory of Mind] calculations' (188). Critical modernist approaches to popular film sometimes object to identification strategies which are perceived as manipulative and to critique them by pointing to the ways in which a hierarchy of experience is created through them. It is thus important that the film is seen to counter the tendency to represent the issues systematically from one point of view.

The suffering of the shark is another subjectivity that can be explored, a position that is encouraged by the subsequent sequence in which a finless shark is rested on the side of the boat and pushed into the water, where an underwater shot shows it falling, lifeless to the floor. Another shark body is shown writhing as it descends. The slaughter of animals for food has historically repeatedly been represented as a revelatory image at the heart of human society. One of the most well known 
examples, Georges Franju's surrealist documentary Le Sang des bêtes (1949), about the slaughterhouses of Paris presents the images as the hidden secret of civilization. And yet this hidden secret is revealed again and again in documentaries that are either ambivalent about or against the killing of animals for food. The Animals Film (Myriam Alaux and Victor Schonfeld, 1981), a documentary about the inhuman treatment of animals made in the 1980s in an effort to shift the philosophical and ethical understanding of animal life, shows at the beginning one of the earliest film images of animal torture, an image made by Edison of the electrocution of an elephant. Nikolaus Geyrhalter's recent film Unser täglich Brot (Our Daily Bread, 2006) show the most high tech forms of slaughter in high definition. It hardly seems credible then, that these facts are not part of a shared cognitive environment and yet as the images are shown they appear each time to be something new.

In his book surveying the history of modern ideas in relation to the figure of the animal, Akira Mizuta Lippit (2000) has discussed how identity with the image of an animal, and with a dying or dead animal in particular, is possible. He recounts an interview in which the artist Francis Bacon speaks about his responses to photographs of slaughterhouses and meat. Lippet interprets Bacon's description of his response as identification with the soon-to-be-slaughtered animals. And yet, for the history of philosophical understandings of animal being, the animal is not a subject in the way a human being is. Lippet continues:

Since the animal possesses no discernible subjectivity, the human subject cannot rediscover itself in the place of this other. Although a human being can project anthropomorphic characteristics onto the animal or experience emotions (such as pathos or sympathy) in response to its being, an impenetrable screen-language-divides the loci of animal and human being. If Bacon has indeed effected an identification with this image, then where does one locate the source of Bacon's identification, in the animal or in the photograph? (179)

This bring the discussion back to the opening scene in which the director and the shark were physically touching, raising questions about the nature of this contact between human and animal. Lippet's discussion extends these questions to the image, where the spectator and the animal do not touch but where the spectator 
alone is confronted with the image of the animal. Lippet argues that: 'the combination of the animal subject and the photographic image alters in some essential fashion the structure of identification' (179) The photographic image, as a mechanical reproduction and the animal, lacking subjectivity, both block 'the dialectical flow of subjectivity' or as we might understand it here, the assumption that the cognitive environment is shared. Lippet uses a terms developed by Gilles Deleuze and Felix Guattari to capture the unity of the image with which the viewer can nevertheless identify, 'as a rhizome, animals and photographs appear to found and animate an entirely other topology: one that allows for an economy of the gaze, identification, and becoming' (179).

What Bacon discovers through his identification is, according to Lippet 'a totemic and sacrificial economy' (179) in which the animal figure is 'in a state of perpetual vanishing' (1) representing radical alterity itself, defining the boundary of the human and banishing non-human subjectivity to the realm of forgetting. The image of the dismembered and slaughtered animal in Sharkwater is a testament to an old industry that does not identify the shark as a subject, that identifies it as a hostile predator, and values a certain type of soup made from its fins for its status value, and the dead body of the animal for its potential to transmit health and strength in the form of medicine. The film seeks to diminish these values for the sake of the living body of the shark and the continuation of the species. In its place it attempts to promote a possible sense of identification with the living rather than the dying body of the shark by using the tactility of the moving image, by including the human and the shark in the frame, and by visualising a community of people prepared to campaign for shark protection.

It is a further scene, however, built up to as a climax in the film, that moves away from the issues of sympathy or empathy with the shark to assert instead identity with other human beings who are prepared to protect the shark. The scene follows a long sequence in which the director is confined to his hospital bed with a bacterial infection that threatens him with the removal of his leg. A poetic interpretation of his plight might see the parallels between the dismembered sharks and his own awareness of his vulnerable body. His sense of empathy is given by chance a physical ground. The extended shots of Stewart in hospital were interpreted by Margaret Pommeranz, reviewing the film for the Australian Broadcasting Corporation 
(ABC), as narcissistic (2011), but they chime with the development of the film away from the wildlife documentary, towards the activist film, and then towards the visualization of an extended global environmental community beyond the passionate few.

Whilst in hospital the haven for sharks off the Galapagos islands has gone, leaving the coast of Costa Rica as the last place of protection. His return to the country, determined to celebrate the saving of his leg by swimming with the sharks again, is accompanied by images of a demonstration. Stewart explains: 'Costa Ricans were rallying against shark-finning. The publicity surrounding our case brought the sharkfinning industry into the spotlight. We hadn't totally failed in saving sharks. We helped to awaken a country and people. Costa Ricans were outraged. They held protests against the private docks and spoke out against the corruption. The world had started rallying for sharks.' Within the story, this demonstration is represented as a surprise, an unexpected outcome of the action of attempting to stop illegal fishing off the coast of Costa Rica. The mobilisation of people is thus represented as spontaneous and democratic rather than manufactured. This impression tallies with the approach that presents a personal point of view while engaging with others, in that it represents the dedication of the film director as personally, rather than institutionally, motivated. This is important to the ethos of the film as a whole as it strives for a metarepresentation that is convincing.

Returning to Sperber's discussion on the development of human cognition and communication, the goal of the film is to demonstrate a genuine need for a collective ban and reinforcement of the ban on fishing despite the loss of employment and revenue that such a ban would entail. Given that the context is global and the advocate North American, it is not surprising that there should be some scepticism about the need for some to make sacrifices for all. Sperber speculates that alongside a tendency to trust only known others, and to look for emotional and body language cues for indications of lying, abstract reasoning evolved as a means to test whether other humans were honest and genuine in their communications. As a 'protective mechanism against misinformation' he speculates that an ability developed that involved checking for internal consistency, with a corresponding ability to signal consistency in language through terms (in English for example) such as 'and', 'or', 'if', 'but', 'therefore'. 
The next step in the persuasion-counterpersuasion arms race is the development of the ability to scrutinize these argumentative displays, and to find fault with them. In other terms, I am surmising, on evolutionary grounds, the development of a very special kind of "logical", or logico-rhetorical ability. It is special in that it attends to logical relationships not per se, nor for the sake of the benefits that good reasoning can give the individual thinker, but as a means to filter communicated information, and, on the other hand, as a means to penetrate the filters of others.

The final sequence of the film, as is typical for environmental documentaries of this kind, reinforces through talking heads some of the points made throughout the film about the environmental movement with a conclusion from Stewart himself arguing that sharks are essential to human survival. The film thus returns to its original position, placing its truth in the first person perspective of an institutionally independent filmmaker and scientist, who shows himself speaking and carrying out tasks such as filming in the film, and who selects arguments put forward by environmental scientists and activists like himself. In addition, it is asserted that the demonstrators hold the same opinions, 'People in Costa Rica weren't just rallying for sharks. They were rallying for life and for us' (2006) Demonstrating consistency, the final shots show sharks in their natural environment.

\section{Conclusion}

The film form demonstrated in Sharkwater is one that attempts to negotiate many different problems encountered in the effort to raise an appropriate awareness of environmental issues and to stimulate active engagement in the solution of problems. In its choices about including the human and the animal in a shared physical environment, and in its representation of a first person account of the journey towards activism, it creates a framework for audiences to engage in and test various cognitive positions presented by the film and to compare these with knowledge already held.

Although persuasion is an activity displayed throughout the film in the words and actions of the participants, important to its overall argument is the representation of the physical world of the shark as well as the body of the shark that is under threat. This footage is represented as part of a structure which represents the world of the 
shark as part of and continuous with the world of the human. It also represents the human world as interconnected and global. The film relies on human cognition to recognize the position of the filmmakers and their intention to persuade, but at the same time to allow the viewer to develop on from the film and perhaps to form a contrary opinion on the basis of what is represented. The possibility of viewing the information presented from various points of view enables a process of testing for consistency and for hidden motivations. The representation of demonstrations moves the argument away from the first person to the collective point of view again stressing the nature of the information presented as public, shared and testable.

A commentator at the end of the film remarks on how much is already known: 'We know what we are doing. The scientists know, the environmentalists know, the companies know, and the general public know, and yet we are allowing ourselves to do this.' This statement is an assertion of the point of view that the film and environmental research is not about knowledge per se. Sperber and Wilson argue that it is a human goal to increase knowledge about the world. They also argue, however, that human beings pay attention to each other's communicative efforts in the expectation of relevance - that the intention to communicate comes with a guarantee of cognitive effects that will increase or alter in some way an individual's existing cognitive environment. This idea, that the creation of a mutual cognitive environment is an effective way to raise awareness of environmental issues, points back to the shared physical environment from which knowledge comes. It is thus all the more important that the film represents, alongside the known statistics about the decline in shark numbers, the potential for change through the demonstration in Costa Rica and through the information that the Galapagos Islands have been reinstated by the community as a safe haven. This information reinforces the visual representation of a physical environment that is shared, and of a cognitive environment that is developing, making environmental issues more visible, and envisaging greater cooperation between individuals and across communities.

\section{References}

Anderson, J.D. 1996. The reality of illusion: an ecological approach to cognitive film theory. Carbondale and Edwardsville: Southern Illinois University Press. 
Blewitt, J. 2010. Media, ecology and conservation: using the media to protect the world's wildlife and ecosystems. Foxhole, Dartington, Totnes: Green Books

Bousé, D. 2000. Wildlife films. Philadelphia: University of Pennsylvania Press.

Branigan, E. 2006. Projecting a camera: language-games in film theory. New York, London: Routledge

Buckland, W. 2000. The cognitive semiotics of film. Cambridge: Cambridge University Press.

Christensen, C. 2009. Political documentary, online organization and activist synergies. Studies in Documentary Film 3, 199-218.

Cubitt, S. 2005. EcoMedia. Amsterdam, New York: Rodopi.

Fothergill, A., Holmes, M., and Byatt, A. (Producers). Originally transmitted 12.09.0131.10.01. The Blue Planet. UK: BBC Worldwide; 2 entertain.

Grodal, T. 2006. The PECMA Flow: A General Model of Visual Aesthetics. Film Studies 8), 1-11.

Grodal, T. 2009. Embodied Visions: Evolution, Emotion, Culture, and Film, Oxford: Oxford University Press.

Kollmuss, A., Agyeman, J. (2002): Mind the Gap: Why do people act environmentally and what are the barriers to pro-environmental behavior? Environmental Education Research 8, no.3, 239-260. http://dx.doi.org/10.1080/13504620220145401 (accessed August 30, 2011).

Laclau, E. and C. Mouffe 2001. Hegemony and socialist strategy: towards a radical democratic politics. London and New York: Verso

Lippit, A.M. 2000 Electric animal: Toward a rhetoric of wildlife. Minneapolis: University of Minnesota Press.

Marks, L.U. 2002. Touch: sensuous theory and multisensory media. Minneapolis: University of Minnesota Press.

Pomeranz, M. 2011. Sharkwater review for the ABC website http://www.abc.net.au/atthemovies/txt/s2229519.htm (accessed August 30, 2011).

Sharkwater Productions. 2008-9. Shark Education. http://www.sharkwater.com/education.htm (accessed March 27, 2011). 
Sharkwater: the truth will surface. Directed by Rob Stewart. Toronto ON: Sharkwater Productions.

Sharkwater: beneath the surface. (DVD bonus 2008a) Horizon Motion Pictures.

The making of Sharkwater. (DVD bonus 2008b) Horizon Motion Pictures.

Sobchak, V. (1991) The Address of the Eye: A phenomenology of film experience, Princeton: Princeton University Press

Sperber, D. 2000. Metarepresentations in an evolutionary perspective. In Dan Sperber ed. Metarepresentations: A Multidisciplinary Perspective. Oxford University Press, 2000, pp.117-137. http://www.dan.sperber.fr/?p=53 (accessed August 30, 2011).

Sperber, D. \& D. Wilson (1986/1995). Relevance: Communication and Cognition. Oxford: Blackwell.

United Nations Environment Programme. 1972. C: Action Plan. Retrieved November 27, 2010, from United Nations Environment Programme: http://www.unep.org/Documents.multilingual/Default.asp?DocumentID=97\&Art icleID $=1512 \& \mid=e n$

United Nations. 1972, December 15. Report of the United Nations Conference on the Human Environment. Retrieved November 2, 2010, from United Nations Environment Programme:

http://www.unep.org/Documents.Multilingual/Default.asp?DocumentID=97 